\title{
O Currículo da Classe Hospitalar Pioneira no Rio Grande do Sul
}

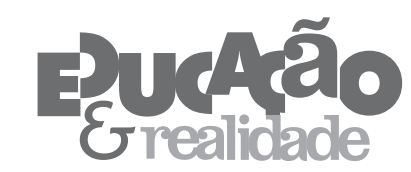

Leodi Conceição Meireles Ortiz'

Soraia Napoleão Freitas'

'Universidade Federal de Santa Maria (UFSM), Santa Maria/RS - Brasil

RESUMO - O Currículo da Classe Hospitalar Pioneira no Rio Grande do Sul. Este artigo é parte da tese de doutorado que teve como objetivo geral conhecer o currículo da Classe Hospitalar pioneira no Rio Grande do Sul. Para tal intento, a pesquisa trilhou os caminhos metodológicos da abordagem qualitativa, tendo como lanterna sinalizadora a corrente de pensamento fenomenológica. As feituras educacionais desta classe, nomeada como Programa de Apoio Pedagógico (PAP), anunciaram o empoderamento de descendência curricular crítica, contudo, há uma abertura consentida aos pressupostos advogados pela abordagem pós-crítica. A Classe Hospitalar disponibiliza, em seu território de ensino, a aprendizagem de conhecimentos, valores e vivências, professando a tessitura de um currículo impregnado de vida. Portanto, ao longo do projeto educacional da classe pioneira pautado em contingência emancipatória -, vê-se a observância do respeito à dignidade, aos valores sociais, à produção cognitiva e ao estado clínico-emocional de cada paciente. O aluno como sujeito político, solidário, conhecedor, inventivo, cidadão e livre, eis a entidade sonhada e tencionada pela prática curricular desta Classe Hospitalar pesquisada.

Palavras-chave: Classe Hospitalar. Currículo. Educação.

ABSTRACT - The Curriculum of the Pioneer Hospital Class in Rio Grande do Sul. This article is part of the doctoral thesis that aimed to meet the curriculum of Class Hospital pioneered the Rio Grande do Sul For this purpose, the research trod the paths of methodological qualitative approach as a flashlight signaling the phenomenological school of thought. The educational feituras this class, named Educational Support Program (PAP), announced the empowerment of descent critical curriculum, however, there is an opening consented to the assumptions advocated by post-critical approach. The Class Hospital provides in its territory of teaching, learning skills, values and experiences, professing the fabric of a curriculum infused with life. Therefore, throughout the project's educational pioneer class guided by contingency emancipatory - see the observance of respect for dignity, social values, the production and the cognitive-emotional medical condition of each patient. The student as a political subject, supportive, knowledgeable, resourceful, and free citizens, that is the entity dreamed and tensioned by the practice of this curricular Hospital Class searched. Keywords: Hospital Class. Curriculum. Education.

Educação \& Realidade, Porto Alegre, v. 39, n. 2, p. 595-616, abr./jun. 2014.

Disponível em: <http://www.ufrgs.br/edu_realidade> 


\section{Aquilo que se Anuncia como Primeiros Manifestos}

Ao ser estabelecido um fio condutor temporal, a legitimidade da ação das classes hospitalares vem respaldada por um rol de políticas que datam o ano de 1994, com a Política Nacional de Educação Especial (Brasil, 1994a) e o Plano de Expansão e Melhoria da Educação Especial (Brasil, 1994b). Esses documentos preconizaram as classes hospitalares como sendo uma modalidade de ensino direcionada a crianças hospitalizadas.

Em 1995, os Direitos da Criança e do Adolescente Hospitalizados (Resolução n. 41, de outubro de 1995, do Conselho Nacional dos Direitos da Criança e do Adolescente) asseguraram a garantia desta parcela de desfrutar alguma forma de recreação, programas de educação para saúde e acompanhamento de currículo escolar durante a permanência hospitalar (Brasil, 1995).

Em 2001, foram instituídas as Diretrizes Nacionais para a Educação Especial na Educação Básica (Brasil, 2001), que asseverou, em seu artigo 13, parágrafo $1^{\circ}$, a incumbência das classes hospitalares em oportunizarem a continuidade ao processo de desenvolvimento e aprendizagem de alunos matriculados em escolas da Educação Básica, contribuindo para o retorno e a reintegração ao grupo escolar, e desenvolver currículo flexibilizado com crianças, jovens e adultos não matriculados em sistema educacional local, facilitando seu posterior acesso à escola regular.

Recentemente, entraram em vigor as Diretrizes Operacionais para o Atendimento Educacional Especializado na Educação Básica, modalidade Educação Especial, que prescreveu, em seu artigo $6^{\circ}$, a Educação Especial em caráter complementar ou suplementar nos casos de Atendimento Educacional Especializado em ambiente hospitalar ou domiciliar, sob responsabilidade do respectivo sistema de ensino (Brasil, 2009).

Pelo histórico legal, percebe-se que as classes hospitalares são amparadas por aportes relativamente recentes e que o amadurecimento de sua vocação educacional dar-se-á na medida em que sejam executadas as recomendações que os documentos oficiais preconizam.

Partindo da tese de que há currículo gestado nas classes hospitalares, torna-se dizível a justificativa desta investigação: a importância em deixar ver o fenômeno do currículo da Classe Hospitalar pioneira no Rio Grande do Sull ${ }^{1}$, nomeada como Programa de Apoio Pedagógico (PAP) do Hospital de Clínicas de Porto Alegre.

Assim, o estudo filia-se ao princípio da igualdade de direitos e à vanguarda na reflexão acerca da universalização do acesso à escola às crianças com problemas de saúde e participação destas no entorno social.

Ao ser procedido o Estado da Arte, em consulta ao portal da Coordenação de Aperfeiçoamento de Pessoal de Nível Superior (CAPES) e 
após levantamento de 397 estudos sobre currículo na Biblioteca Digital Brasileira de Teses e Dissertações (BDTD), foi constatada a inexistência de estudos curriculares sobre classe hospitalar. Fato similar ocorreu, também, na busca efetuada aos artigos cadastrados no site da Scientific Electronic Library Online (Scielo).

Estes levantamentos confirmaram, o território de ausências envolvendo a temática do currículo das classes hospitalares, portanto é preciso deixar ver o arranjo curricular presente na atuação do atendimento escolar em ambiência hospitalar.

Currículo é o que se diz e se faz com ele, por ele e nele, ou seja, uma entidade de linguagem e por isso, configura-se num campo constituído por conhecimento e por saberes ou por práticas entendidas em sentido mais amplo.

O currículo, percebido como uma rede portadora de sentido, refere-se aos conteúdos da escolarização, a seleção e a organização do conhecimento escolar. Este processo de selecionar e organizar demanda a feitura de transformar saberes sociais em saberes escolares, satisfazendo, portanto, um estágio de conversão da cultura em "cultura escolar" para a obtenção do status de reinvenção desta mesma cultura.

A escola, como também a classe hospitalar, produz saberes/conhecimentos, traduzindo-os em disciplinas que têm como foco o conhecimento para aprendizagem e ensino. E é justamente do poder exercido pelos saberes escolares nas decisões dos rumos da cultura da sociedade que a reflexão acerca do currículo se ocupa.

\section{Classe Hospitalar: (re)afirmação de seu território pedagógico}

O Ministério da Educação, através da Secretaria de Educação Especial, lançou em 2002 o documento Classe Hospitalar e Atendimento Pedagógico Domiciliar: estratégias e orientações, tendo como escopo a universalização do atendimento escolar.

E é precisamente este artefato que foi utilizado aqui como um mapa-base, tendo como pontos de referência os princípios e fundamentos, objetivos, organização administrativo-pedagógica e recursos humanos, para serem acrescentados os achados recentes.

A partir de mapeamento veiculado por Fonseca (2002, p. 205) há 74 hospitais brasileiros que disponibilizam assistência educacional a seus usuários. Assistência esta, que envolve o exercício pedagógico de 140 ensinantes e o exercício discente de 2100 crianças e jovens hospitalizados.

Seguindo as estratégias e orientações presentes no documento citado acima (Brasil, 2002), o atendimento educacional hospitalar deve estar vinculado aos sistemas de educação, como unidades de trabalho pedagógico das Secretarias Estaduais e Municipais de Educação e do

Educação \& Realidade, Porto Alegre, v. 39, n. 2, p. 595-616, abr./jun. 2014. 597 Disponível em: <http://www.ufrgs.br/edu_realidade> 
Distrito Federal, como também às direções clínicas dos sistemas e serviços de saúde. Compete às Secretarias de Educação atender à solicitação dos hospitais por este serviço, contratando e capacitando docentes, bem como provendo recursos financeiros e materiais.

Para Caiado (2003, p. 71), o trabalho pedagógico no ambiente hospitalar é um “[...] espaço em construção”. Significa dizer que não há mapas com legendas a serem seguidos, orientações que levem a uma localização definida, ou mesmo a um porto seguro em que possam sedimentar as certezas.

O que há é a ousadia em transgredir, vislumbrar a emancipação do disciplinamento dos corpos e mentes inculcados no universo asséptico e silencioso dos hospitais. Talvez recaia aí a principal justificativa do trabalho pedagógico - invadir o objetivo mundo branco para legitimar a provisoriedade, a subjetividade e o poder de transformação que a educação postula neste cenário.

Usufruir do direito de participar das atividades na classe acenam para o doente o estado de normalização de algumas ansiedades próprias de um ser curioso - que deseja dominar o entorno desconhecido -, desmistificando ambientes e o jogo de relações; e a possibilidade de serem recuperadas, no hospital, as suas carências escolares.

A inovação que se persegue com a garantia do direito à educação para alunos com limitações de saúde é, precisamente, o ajuste do foco de concepção do sujeito adoecido, o olhar se alonga para vê-lo com integralidade e não mais fragmentado como um conjunto de peças anatômicas.

A profilaxia, processualizada na classe hospitalar, visa o combate ao fracasso e à exclusão infanto/juvenil do processo de escolarização que pode ser gerada pela estigmatização da doença ou efeitos colaterais da mesma, afastamento da escola devido à necessidade de internação ou do próprio tratamento ambulatorial, vitimização do adoecido pela escola e, finalmente, a fragilização do domínio de conteúdos decorrente do excessivo número de faltas na volta às aulas.

Este combate de possíveis reprovações, evasões e exclusões, proporcionado pelos atos pedagógico-educacionais hospitalares, nada mais é do que a legalização da política de educabilidade a todos; portanto, o legítimo estatuto da escola cidadã.

Na arquitetura conceitual acerca da temática, as vivências educacionais em ambiência da saúde são legitimadas pela intervenção de dois protagonistas - aprendente e ensinante.

No hospital, a criança e o jovem são identificados por um número, uma patologia, um protocolo médico, onde é esperado o esquecimento de sua subjetividade em nome das certezas depositadas nas ciências clínicas.

A atmosfera hospitalar aprisiona o corpo e a racionalidade do ser doente, não permitindo seu livre trânsito e seu ingresso escolar, sufoca- 
-o no ócio, cria laços de dependência, invade sua privacidade e ele perde o direito decisório de pertencimento de si.

O que está sendo pleiteado, neste locus de ensino, é atribuir ao educando o status de sujeito de seu conhecimento, que ultrapasse os limites do diagnóstico clínico e revele todas as suas potencialidades de ser, não o que o dicionário afirma em seu verbete paciente: resignado... que suporta males... que revela paciência, mas ser (im)paciente, um aprendiz autônomo que tem pressa para se apropriar dos saberes fugazes e ser senhor de sua vida.

Neste lugar de solidão, a criança e/ou jovem temporário ou cronicamente adoecido, busca alguém que possa deixá-lo seguro e amparado em sua necessidade de falar de si e de seus mistérios pessoais. É neste momento que a figura do professor sobrevém aos demais profissionais, pois ele, um novo personagem na equipe de saúde, pertence a dois mundos - o escolar e o hospitalar.

Além dos desdobramentos políticos, pedagógicos, psicológicos, sociais e ideológicos, o ofício de mestre incorpora a responsabilidade de traduzir o universo consensual do paciente com suas histórias de vida, seus conhecimentos acerca da doença e saúde e o universo reificado do saber científico da área médica, transformando-os em fundamentos de ensino-aprendizagem. Logo, esta postura de escuta respeitosa de saberes credita à educação a possibilidade de presentificar-se na agenda da humanização em saúde.

Estar com o outro e para o outro; exercitar a escuta quando o educando deixa ver toda a sua tristeza ou felicidade e inaugurar sistemas que aproximem/integrem a realidade escolar com a realidade da saúde são situações reveladas no gozo das atividades pedagógicas, e que dão para os protagonistas do processo educativo as certezas da continuidade da vida e a busca de sentidos para o presente e futuro de ambos. Portanto, são práticas docentes de intervenções para realizar nos sujeitos humanos as predisposições de seres humanos.

Há uma intenção declarada, a educação despoja-se de sua vertente tradicional de ensino formal e lança uma nova prática do olhar e da escuta, respirando ares saudáveis do entorno onde está sediada.

Na pauta metodológica do atendimento educacional em hospitais há a oportunidade de dois agendamentos: a) Nas internações eventuais, a atenção escolar está mais focada nas dificuldades de aprendizagens manifestas na execução das atividades enviadas pela escola de origem ou nas tarefas propostas pela própria classe hospitalar; e b) Nas internações recorrentes e/ou prolongadas, o investimento maior recai no planejamento de ensino, tendo o cuidado de vislumbrar a continuidade da vida acadêmica do estudante.

Na dinamicidade da promoção deste ensino, uma ferramenta didática singular que permeia todo o mosaico de cognição, sensibilidade, pensamento e influências clínicas, corporificando o exercício do apren- 
dizado em ambiência da saúde, é a escuta pedagógica, expressão esta cunhada por Ceccim et al. (1997).

A escuta pedagógica não é uma mera audição, mas uma escuta que implica em apreensão/compreensão dos muitos sentidos presentes no ato de revelar-se ao outro. Significa, ainda, aventurar-se no provisório, saber dialogar com o mistério, despojar-se das certezas, penetrar nas sombras, surpreender-se com o visível e o invisível na comunicação dos sonhos e desejos.

Para muito além dos muros do formalismo, a metodologia própria para a atenção escolarizada na classe hospitalar flutua em direção a uma educação para o afeto ao lado da educação para o conhecimento. A afetividade e a lógica racional não são habitantes de mundos separados e intransponíveis. É, pois, uma premissa balizada por Fontes (2004, p. 280) na iniciativa de "[...] religar os saberes da escola com os saberes da vida, como ferramentas de solidariedade para os sofrimentos e esperanças humanas [...]".

As experiências de conhecimento são tecidas de forma plural, o valor do conteúdo não está aprisionado a si mesmo, e sim articulado a outros, sofrendo intervenções do infantil/jovem escolar e do educador.

A escola hospitalar configura-se como um espaço onde os estudos sistematizados circulam não de forma absolutizada. Nela, a cognição e o prazer em aprender assinam acordos de dialogicidade para garantir caminhos desimpedidos nesta paisagem pedagógica.

O programa de educação hospitalar sinaliza, também, para uma dimensão mais individualizada, já que o exercício de ensinantes potencializa o encontro, a escuta pedagógica e a saúde educacional. Sendo assim, os processos avaliativos deveriam cumprir ideários mais focados no registro de desempenhos e vivências educativas de cada aprendiz.

\section{Perspectiva Histórica do Currículo: tessitura do campo}

O estudo revisitou o passado para nele encontrar testemunhos que documentem a herança curricular, tendo Goodson (2001, p. 22) como conselheiro: "Entender a criação de um currículo é algo que deveria proporcionar mapas ilustrativos das metas e estruturas prévias que situam a prática contemporânea".

Currículo é aqui entendido como um artefato social, cultural e histórico, suscetível a flutuações e mudanças. Ele não é fruto de um processo evolutivo pacífico, neutro ou ingênuo, mas antes uma revelação das rupturas e descontinuidades, um vestígio dos conflitos e ambiguidades travadas para garantir a validação e legitimidade de um campo do conhecimento. Desdobramento observado na manifestação de Saviani (2006, p. 33) com base nos estudos da história curricular:

[...] como construção social, o currículo resulta de processos conflituosos e de decisões negociadas [...] E compreende 
a ideia de que a elaboração e a prática curriculares, envolvendo situações conflituosas, estão mais para soluções negociadas que para soluções consensuais.

Pela etimologia, a processualidade do termo currículo acusa vários sentidos adquiridos no rearranjar do tempo. Com descendência latina, esta palavra vem do termo Scurrere (correr, curso), ou seja, um curso a ser seguido, uma prescrição.

No contexto educacional, principalmente na Paris renascentista e em Glasgow, o termo agregou-se à expressão classe, demonstrando a filiação com a vertente sequenciada, disciplina ou ordem estrutural de classe, controle e seu poder de diferenciar.

Em fins do século XVIII e início do XIX, por inspiração da Revolução Industrial, o sistema de classes foi dando lugar ao sistema de salas de aula. A educação deixou de ser individualizada para atingir o coletivo. Os territórios curriculares passam a ser elementos institucionalizados de diferenciação social - currículos clássicos destinados aos filhos de famílias com boa renda; currículos menos clássicos e mais práticos, aos filhos de classes mercantis e currículos básicos para filhos de pequenos proprietários rurais, comerciantes e artesãos compreendiam as habilidades de ler, escrever e contar - isto posto na escolarização secundária. Já os filhos dos operários permaneciam em escola elementar, aprendendo apenas os rudimentos da leitura, escrita e aritmética (Goodson, 2001).

Na Inglaterra, começo do século XX, pelas demandas de horários e aulas compartimentalizadas, o sistema de sala de aula fez surgir a matéria escolar, ou seja, na Era Moderna a matéria escolar assume papel de prerrogativa do texto curricular. Mais tarde, a supremacia da comunidade universitária fez emergir a definição das disciplinas como uma demarcação de suas especificidades e poder do conhecimento vislumbrado nas universidades (Goodson, 2001).

O movimento histórico traz registros da ambivalência, presente nas discussões americanas e inglesas, que passaram a vigorar nas décadas de 1960 e 1970. Na disputa que se instalou, figuram, de um lado, as teorizações curriculares, consideradas prescritivas e meros programas utópicos, ou seja, carregavam o estigma de práticas idealizadas, que não olhavam o currículo existente; de outro lado, era refletido, lapidado e posto em ação nas escolas - ação curricular.

O mal-estar presentificou-se na seara educacional, o litígio entre teoria e prática imobilizou os estudiosos, que acusaram ser a teoria o algoz da realidade curricular. Houve, então, um endeusamento do prático em detrimento do abstrato.

Na esteira do pensamento da época, a crítica era posta a determinadas teorias prescritivas, produzidas e alinhavadas com projeto ideológico-econômico; em ato contínuo, abriram-se as portas, inadvertidamente, para a redenção do campo da ação e a emergência dos projetos de inovação curricular.

Educação \& Realidade, Porto Alegre, v. 39, n. 2, p. 595-616, abr./jun. 2014. 601 Disponível em: <http://www.ufrgs.br/edu_realidade> 
O Currículo da Classe Hospitalar Pioneira no Rio Grande do Sul

Na tentativa de pacificação, cabe, neste momento, proceder escuta à narrativa de Goodson (2001, p. 55):

Ficamos de posse de uma mensagem fundamental. Se é para ser útil, a teoria curricular deve começar com estudos que se concentrem sobre escolas e ensino. A nossa teoria precisa desenvolver-se a partir do entendimento do currículo tal como é elaborado e realizado e como, ao longo do tempo, vem sendo reformulado. Em síntese, não necessitamos de teorias sobre prescrições curriculares, mas de estudos e, eventualmente, de teorias sobre elaboração e aplicação de currículo.

Ao longo dos séculos, a reflexão sobre currículo fomentou vários embates epistemológicos comprovando a fertilidade teórica deste campo, lembrando que eles não transitam apenas no universo epistêmico, mas também na busca da obtenção do caráter consensual, degrau que confere às teorias a legitimidade hegemônica.

Cada teoria do currículo moderno irá privilegiar uma rede de saber/fazer que atesta o seu manifesto de poder.

As teorias tradicionais incumbem-se de responder às questões $o$ $q u \hat{e}$ ? e como? ensinar, vestindo uma roupagem organizacional, enquanto que as teorias críticas e pós-críticas são recorrentes na questão por $q u e ̂$ ?, tirando os véus do conhecimento selecionado e da subjetividade ou identidade subjacente ao mesmo, num processo comprometido de desocultamento das relações de poder.

Na Teoria Tradicional o processo educacional era comparado ao processo de produção, mapeavam-se as habilidades necessárias às respectivas ocupações, estabelecia-se um rol curricular que desenvolvesse estas habilidades levantadas, para finalmente, proceder-se ao planejamento e à elaboração de instrumentos de aferição quanto à precisão da aprendizagem. O aluno, por sua vez, era concebido como uma matéria bruta a ser lapidada para tornar-se um produto eficiente. O currículo escolar estava associado às funções de controle, organização, mecanicismo, burocracia, padrão e técnica, por isso a expressão desenvolvimento curricular.

Tal paradigma ateve-se aos cuidados do planejar - objetivos, experiências educacionais e avaliação - sempre atento aos princípios da gestão administrativa e de seus desempenhos esperados de eficácia-eficiência. A lógica reinante, nesta escola teórica, é a formação de um homem aparelhado para pensar, agir com segurança e eficácia para, enfim, produzir resultados eficientes na solução das necessidades sociais. Portanto, o homem deveria ser um interventor racional na herança histórica, cultural, educacional e social.

O caráter técnico-prescritivo desta arquitetura de currículo tradicional sinaliza para uma vertente supostamente neutra e ingênua, pregando, assim, a acomodação alienada e a negação ao enfrentamento aos arranjos educacionais e às possíveis dominações culturais e sociais. 
No Brasil, com a abertura política, os estudiosos começaram a ter acesso a um aparato conceitual mais progressista. Esta literatura pedagógica fez nascer, no final da década de 1970, a Teoria Curricular Crítica no país.

No término da década de 1970, com a Teoria Crítica, há um esforço mais sistematizado em lançar um novo discurso no contexto do currículo, não mais planejamento, implementação, controle, objetivos comportamentais, cientificidade na avaliação e realce na pesquisa quantitativa na Educação, e sim o exame na relação existente entre o corpo do currículo e a estrutura social, cultura, poder, ideologia e controle social.

A aceitação ao novo paradigma não se deu de imediato. Os especialistas adotaram, em princípio, uma linha de denúncia e crítica ao currículo anterior, absorvendo a posteriori as influências publicizadas acerca das novas tendências americanas e inglesas do currículo e mesmo da obra de Paulo Freire.

Em 1986, é publicado o artigo Interesses Humanos e Paradigmas Curriculares, de José Luiz Domingues, sendo considerado o primeiro marco no campo brasileiro. O segundo marco no campo curricular brasileiro foi atribuído ao artigo de 1990, de Tomaz Tadeu da Silva, incorporado, em 1992, como capítulo do livro O que Produz e o que Reproduz em Educação: ensaios de sociologia da educação. Este artigo representou uma análise dos 20 anos da teorização crítica e sua contribuição na tessitura de uma sociedade democrática.

No século XX, esta teoria abrigava duas linhas de pesquisa: a) uma, hegemônica até os anos 80 e conveniada aos ideários neo-marxistas; e b) outra, com mais visibilidade nos anos 90, agrega contribuições de diversos estudos que abordam as temáticas acerca de feminismo, raça, estudos culturais, pensamento pós-moderno e pós-estrutural.

A crise da Teoria Curricular Crítica instalou-se, não por este último convívio modernamente absorvido por esta teoria, pois na interpretação de Moreira (2005, p. 27) “[...] a teoria crítica de currículo se tem beneficiado da inclusão de novos aportes, o que sugere que o diálogo entre 'neos' e 'pós', apesar das dificuldades que levanta, pode também ser proveitoso", mas, antes, pelo abismo que se criou entre a produção teórica e a realidade da escola. Portanto, o discurso sofisticado do campo não legitimou a construção de espaço escolar qualificado.

Como medida revitalizadora da Teoria Crítica, caberia a tradução crítica do pós-modernismo, sem o abandono do projeto emancipatório; assim fazendo, os componentes críticos das duas tradições se reconstruiriam, honrando o princípio dialético, para dar conta dos contornos da organização escolar.

As Teorias Pós-Críticas forneceram uma visão alargada das narrativas de dominação. As vozes silenciadas no currículo passaram a ser audíveis e deixaram ver o exercício de poder presente nas relações de gênero, sexualidade, raça e territorialidade, negando a unicidade da relação poder-classe social inspirada na Teoria Crítica.

Educação \& Realidade, Porto Alegre, v. 39, n. 2, p. 595-616, abr./jun. 2014. 
Elas acenam, também, como a escola crítica, para o cuidado que se deve ter com as artimanhas da política, mas que o poder não é exercido apenas na política, ele está travestido em muitas formas e disperso na rede social, às vezes mais sofisticado, camuflado e letal.

Neste sentido, Silva (2001, p. 150) alerta-nos que “[...] depois das teorias críticas e pós-críticas, não podemos mais olhar para o currículo com a mesma inocência de antes".

O currículo, hoje, com seu desenho polissêmico, vem potencializado por abordagens pós-formais, pós-críticos e pós-estruturalistas, interpretado com lanterna crítica ampliada e abrigando agendas do multiculturalismo, pós-colonialismo e estudos culturais.

Longe de ser um universo consensual, o currículo, mais uma vez, passa a ser concebido como uma entidade de conhecimento e poder, onde as desigualdades já não sinalizam para as questões apenas de classe social - como na escola crítica - mas, antes, as desigualdades passam pelo reconhecimento das diferenças e identidades de gênero, raça, sexualidade, religiosidade e territorial.

\section{Aquilo que se Diz dos Modos Investigativos}

A pesquisa em educação insinua-se na área das Ciências Sociais e Humanas com o postulado de indagar e construir, com mãos próprias, uma situação vivencial. $\mathrm{O}$ ato da investigação demarca uma aproximação da realidade, desvelando cientificamente uma situação de mundo.

A opção pela pesquisa qualitativa neste estudo justificou-se pela escuta à subjetividade e à apreensão dos significados atribuídos pelos informantes do fenômeno estudado e sabendo-se que há diferentes tipos de abordagens qualitativas, é preciso, pois, anunciar a priori que esta investigação trilhou os caminhos da abordagem fenomenológico-hemenêutica.

A palavra fenomenologia denota as coisas em si mesmas. Como pontua Heidegger (1997, p. 57), o termo tem dois elementos: "fenômeno" e "logos". "Fenômeno" é entendido como mostrar-se, diz o que se revela, trazer para a luz do dia, pôr no claro, isto é, algo que se pode vir a se revelar e a se tornar visível em si mesmo. "Logos" é discurso, discurso definido como "[...] aquilo que deixa e faz ver" a partir daquilo sobre o que discorre. O ideal fenomenológico é a compreensão dos fenômenos da realidade vivida, para que revele o sentido da existência das coisas e o sentido da existência do sujeito.

Para honrar esta intencionalidade, reafirmou-se as etapas da pesquisa educacional fenomenológica sinalizadas por Rezende (1990, p. 58), que anuncia os três momentos associados aos três signos da palavra sentido: a) momento da constatação descritiva da realidade; b) momento da compreensão; e c) momento de projeção-prospectiva. 
O critério da antiguidade e o efetivo exercício da educação hospitalar definiram a escolha da classe hospitalar gaúcha que teve seu início de atividades pedagógicas datadas em 1990. Portanto, a pretensão desta pesquisa foi conhecer o currículo da Classe Hospitalar pioneira no Rio Grande do Sul para construir referencial educacional.

Na seleção da amostragem, foi obedecido o critério da amostra aleatória (sorteio simples) para a escolha de $1 / 3$ dos sujeitos da pesquisa, totalizando seis professores. A coleta de dados utilizou questionário para obter informações junto a este $1 / 3$ de professores integrantes do Programa de Apoio Pedagógico (PAP) - pertencente à Escola Estadual Técnica em Saúde (ETS) - com atuação na Classe Hospitalar do Hospital de Clínicas de Porto Alegre (HCPA).

Por caminhar num trânsito de respeito aos saberes do outro e entender o currículo como uma construção social, as respostas destes sujeitos foram sendo elaboradas nas reuniões pedagógicas a partir de discussões coletivas, registradas em um único documento e enviadas por correio eletrônico.

A pesquisa fez observância dos aspectos éticos, apresentando as figuras do Termo de Confidencialidade (TC) e Termo de Consentimento Livre e Esclarecido (TCLE) como um instrumento balizador do respeito ao sujeito de pesquisa; esclarecimento dos riscos e benefícios; autonomia do sujeito; confidencialidade e privacidade das informações. Assim fazendo, a pesquisa observou o respeito aos princípios das Ciências Sociais e Humanas, de conformidade com a Resolução n. 196/96, do Conselho Nacional de Saúde.

\section{Aquilo que se Mostra para Deixar e Fazer Ver}

Os dados obtidos sustentam pistas que levam a um primeiro achado da investigação: há um desenho curricular esboçado na prática de ensino da Classe Hospitalar (PAP) do Hospital de Clínicas de Porto Alegre.

Por ter sido gestado num momento histórico caracterizado pela grande efervescência no campo do pensamento curricular brasileiro, o desenho curricular do PAP absorveu contornos filiados à vertente curricular crítica, porém aceitando inovações pós-críticas.

Desta forma, revela que, assim como a educação regular no período entre 1980 a 1990 foi sofrendo influências da evolução do empoderamento curricular, a classe hospitalar, por ser um espaço de estudos por excelência, igualmente sofreu as instabilidades produzidas pelas teorias do currículo, legitimando que "[...] o hibridismo do campo parece ser a grande marca do campo no Brasil na segunda metade da década de 1990", como anunciam Lopes e Macedo (2002, p. 16).

A Teoria Crítica advoga, pois, a resistência para que seja instada a manutenção de justiça social, democracia, liberdade e direitos huma-

Educação \& Realidade, Porto Alegre, v. 39, n. 2, p. 595-616, abr./jun. 2014. 
nos. Para esta feitura, atribui valor de mérito, pelas palavras de Moreira (2005, p. 12), nas: “[...] relações entre conhecimento escolar e a estrutura de poder na sociedade mais ampla, abrindo possibilidades para a construção de propostas curriculares informadas pelos interesses emancipatórios [...]".

Neste cenário, emergem as preocupações contra-hegemônicas acerca da educação de crianças e adolescentes enfermos, considerados minorias e excluídos das relações sociais e educacionais.

Diante do exposto, os estudiosos comprometidos com classe hospitalar assumem estandarte de resistência ao poder sedimentado, negando a exclusividade de educação apenas aos alunos "normais" e em escolas, subvertendo as potencialidades educativas para outros endereços como os hospitais e reinventando outros modos de experienciar o conhecimento e as culturas para formar sujeitos políticos - seres inventivos, investidos de conhecimento e senhores de decisão - com atuação autônoma num projeto emancipatório.

Eis, portanto, os motes que aproximaram a gênese da classe hospitalar aos ideais das teorias críticas.

O tempo de criação do Programa de Apoio Pedagógico - 1990 -, período em que a Teoria Crítica com seu veio marxista ainda exercia poder de visibilidade no cenário educacional, acusa seu percurso de ensino trafegando em sintonia com as orientações oficiais de sua época, portanto, fiéis aos princípios críticos.

Nesta linha de especulação, observa-se também que há uma recorrência de expressões - atuação crítica, direito dos cidadãos, cidadania, prática emancipatória - no discurso manifesto pelos docentes, além da inspiração confessa nos pressupostos apregoados por Paulo Freire ao ver o ato pedagógico como ato dialógico.

Tais identidades sociais e individuais, que a classe em estudo propõe, estão firmemente postadas na teorização crítica e evidenciadas no manejo dos ritos pedagógicos e nas tramas contestatórias da leitura de mundo disponibilizada aos alunos adoecidos. A classe hospitalar não faz seus caminhos em vias de regulação e controle e sim trânsito na liberdade, independência e emancipação.

$\mathrm{O}$ PAP confere importância genuína aos conteúdos relativos à progressão do aluno, preferencialmente compatíveis com os desenvolvidos na sua escola de origem, acompanhados de aprendizagem de valores, sendo estes exercitados na arte de conviver para posteriormente atuar de forma autônoma no contexto. É uma visão em tempo atual que ainda demonstra fidelidade ao momento educacional de sua criação, pois, após 1990, acordando com Macedo (2007, p. 42):

[...] o pensamento curricular brasileiro vai optar por uma análise predominantemente sociológica e antropológica, [...]. O currículo passa a ser considerado um texto político, 
ético, estético e cultural, vivido na tensão das relações de interesses educativos protagonizado pelos diversos atores sociais.

A Classe Hospitalar pioneira no Rio Grande do Sul não vê com estranhamento os ritos patenteados na escolarização, assumindo em seu contrato didático a feitura de objetivos, conteúdos, metodologias, recursos, avaliação e expectativas de formação de aluno e sociedade, inspirados na concepção de educação pleiteada.

Na ambiência desta educação em hospital, não há um exclusivismo do enfoque do conhecimento sistematizado e das relações traduzidas no jogo de poder presente na construção da sociedade, pressupostos que retratam a Teoria Crítica. Para além desta postura política, a Classe Hospitalar também faz escuta ao lugar da cultura e patrocina relações de igualdade aos diferentes, caminhos que levam a um alargamento próprio da Teoria Pós-Crítica.

Na seara da educação, as relações de poder e opressão apontados pela Teoria Crítica, inicialmente no âmbito de classe social e da discriminação/libertação do currículo, aos poucos vão dando lugar à passagem de novas influências permitidas através de aproximações do pensamento pós-moderno e pós-estrutural.

Nesse contexto, a Classe Hospitalar insere-se no movimento de transição das correntes curriculares, presente neste cenário educacional híbrido. Num ato conciliatório entre a emancipação e o pós-modernismo, os professores do PAP afirmam que os saberes necessários à docência passam pelo entendimento dos valores sociais de cada paciente e concebem os conteúdos como elementos emergentes do universo experencial dos próprios aprendizes, abordagem esta de descendência freireana. Porém, este coletivo também aceita os novos ares da discussão curricular ao demarcar seus planos de ação, lançando às atividades de ensino-aprendizagem conteúdos de aprofundamento no campo da diversidade social, étnica, de gênero e de religiosidade.

As concepções da Teoria Pós-Crítica desvelaram a opacidade que cerca o exercício do poder e da desigualdade imbricados nas relações de etnia, gênero, raça, religiosidade e territorialidade. Há, nesta teoria, uma desnaturalização do processo de silenciamento e dominação, de acordo com Moreira (2005, p. 22):

À medida que se aprofunda a preocupação com a influência de raça e gênero, além de classe social, nos elementos de discriminação e/ou libertação presentes nos currículos, acentua-se o foco nas contradições, nos conflitos e nas resistências que ocorrem no encontro pedagógico.

Desta forma, a Classe Hospitalar do HCPA reconhece o modo tenso como os indivíduos resistem a estas formas de subjetivação, patrocinando em seus encontros pedagógicos a leitura das contradições e conflitos para traçar caminhos desimpedidos no cumprimento da tes- 
situra das identidades sociais produzidas pelo seu currículo: formação do sujeito defensor dos direitos do cidadão e respeitador das diferenças.

Embora nos universos escolares ainda circulem rudimentos de um discurso de homogeneização, a agenda atual da educação escreve texto emblemático onde vislumbra a riqueza da diferença, porque, no dizer de Garcia e Moreira (2006, p. 13):

[...] na verdade o que caracteriza a sala e aula é a diferença, não é a semelhança [...] a sala de aula deveria ser um riquíssimo espaço de diferentes saberes que se cruzam, entrecruzam, entram em conflito, produzindo novas possibilidades de compreensão do mundo e aumentando a compreensão que cada um pode ter de si mesmo.

O universo escolar do HCPA sublinha esta premissa na sua trilha pedagógica ao anunciar, como objetivos de sua prática, a promoção da inclusão social e o incentivo ao fortalecimento da autoestima, respeitando a igualdade entre alunos e pacientes.

A igualdade, aqui referenciada, passa pela garantia do direito de todos à educação. Tanto o aluno quanto o paciente, nos seus contextos escolares específicos, não são vistos numa operação de subtração de capacidades e conhecimentos, mas, antes, reconhecidos como diferentes. Seres marcados e identificados por suas experiências, culturas e ambientes sociais particulares pois, o PAP procura hospedar em seu território de ensino o convívio tácito entre igualdade e diferença.

Das incursões do trabalho educativo do PAP pelo espaço fronteiriço da Teoria Pós-Crítica emerge seu entendimento acerca da composição de cultura. Concebendo-a como modo de vida de uma sociedade e o fruto do trabalho humano. Não diferencia cultura erudita e cultura popular, dando visibilidade tanto aos conhecimentos acadêmicos e escolares iluminados pela cultura tradicional, humanista e clássica, quanto àqueles conhecimentos cotidianos, locais e da cultura de massa, próprios das classes subordinadas; logo, na expressão de Silva (2001, p. 136), "O conhecimento é um objeto pré-existente: ele já está lá; a tarefa da pedagogia e do currículo consiste em simplesmente revelá-lo”.

Na Classe Hospitalar, em decorrência de sua especificidade, a adesão dos professores e alunos às tecnologias de informação e comunicação comprova a franquia às diferentes culturas e aos contornos de acesso ao conhecimento, pois, segundo Sacristán (2002, p. 66):

\begin{abstract}
Os meios que nos aproximam de outros mundos, de outras vozes e de outros temas são cada vez mais fáceis de transportar para serem usados em contextos muito diversos de aprendizagem, de trabalho ou de descanso, podendo ser integrados em diferentes ambientes vitais por parte dos usuários individuais.
\end{abstract}

Esta relação enamorada entre a Classe Hospitalar gaúcha e as facilidades da tecnologia permite subsidiar informações catalogadas, ati- 
vidades de pesquisa, comunicação rápida e acesso ao conhecimento de diferentes centros; no entanto, há que se manter sob suspeição crítica as verdades coletadas na rede. Elas atendem aos interesses de grupos, objetivam reproduzir o que está posto e não produzir emancipação.

Pela lógica da escola, a tecnologia - concebida como recurso de ensino - pode dar fomento aos currículos escolares; para tal, seria oportuna a orientação de Macedo (2003, p. 58):

Precisamos construir um currículo, que integre o computador, mas que seja um espaço de negociação de sentidos, de geração de ideias, de aceitação da subjetividade, de valorização da experiência. Só assim poderemos subordinar, efetivamente, o computador à diversidade da experiência humana.

Num esforço de deslocamento do estudo, é pertinente, neste momento, sair do campo da teorização do currículo de classe hospitalar para olhar o currículo em ação desta prática educacional no entorno da saúde, uma vez que, projetos educativos tomam forma em atividades localizadas no tempo/espaço determinados, vividos por sujeitos específicos e constituindo projetos curriculares que conciliam, na prática, o viés emancipatório e pós-moderno.

Já que currículo é uma construção social, é preciso, pois, valorizar o fazer curricular como uma produção de sentido. Logo, este estudo mais uma vez recorre ao questionamento: o que professa o currículo da Classe Hospitalar do Hospital de Clínicas de Porto Alegre?

Esta escola constrói um currículo impregnado de vida, um currículo que faz um caminho marginal à sistematicidade da escola regular e sem disciplinamento do conhecimento, do corpo e das vontades e que é capaz de, "[...] transformando o tempo de espera em tempo de construção, de socialização e de aprendizagem” (Uchôa, 2007, p. 166), subjugar as hierarquizações reveladas ou veladas.

Assim fazendo, este currículo passa a ser visto numa concepção mais ampla, não mais como uma mera listagem de conteúdos, mas sim um corolário de conhecimentos voltados ao atendimento das necessidades desta comunidade singular, impregnados pela realidade, pelo contexto social, pela experiência vivida e pela leitura de mundo do aluno. Ou seja, sob o aconselhamento de Assis (2009, p. 162):

O currículo deve ser flexível e multicultural, para possibilitar o atendimento aos percursos individuais dos alunos enfermos e eles se sentirem agentes de seu processo educacional e do seu tratamento, podendo transformar a realidade. [...] fomentando o despertar do desejo de agir e construir, de maneira participativa, valores, atitudes e saberes.

A Classe Hospitalar pioneira do RS com objetivos de: a) construção de conhecimento e inclusão social; b) inter-relação entre professor, aluno e sociedade; c) respeito à igualdade; d) aproximação com a escola

Educação \& Realidade, Porto Alegre, v. 39, n. 2, p. 595-616, abr./jun. 2014. 609

Disponível em: <http://www.ufrgs.br/edu_realidade> 
O Currículo da Classe Hospitalar Pioneira no Rio Grande do Sul

de origem; e e) fazer do ensino um instrumento de qualidade de vida, sinaliza - através de atividades tanto individualizadas, quanto de ordem coletivas - a formação do aluno habilitado intelectualmente, cônscio de seu papel cidadão no mundo e capaz de pensar criticamente o seu processo de adoecimento, as causas e as consequências da doença, como instâncias de valoração social.

Apesar da evolução ocorrida no campo epistemológico educacional, as disciplinas tradicionais continuam presentes na estrutura curricular das escolas do ensino regular e também nos currículos da Classe Hospitalar gaúcha. Porém, uma transformação já pode ser percebida acerca das noções de conhecimento disponibilizadas nas duas moldagens de prática curricular: a escola e a classe hospitalar.

Enquanto Moreira e Silva (2008) afirmam que a escola permanece indiferente à cultura popular (televisão, música, videogames, revistas) com suas economias do afeto e do desejo, relegando-a ao campo das ausências, a primeira Classe Hospitalar do RS incorpora os conhecimentos cotidianos, locais e midiáticos, trazidos pelos seus discentes, para, a partir deste arranjo do senso comum, conduzi-los à aquisição dos conhecimentos científicos.

Este processo de desnaturalização do universo consensual em universo reificado - este também chamado de conhecimentos científicos - além de ser um procedimento didático consagrado, olha com respeito a cultura negada e silenciada.

A valorização não se dá somente no plano da cultura popular. O PAP também propõe, em sua estrutura pedagógica, a pluralidade advinda dos muitos saberes e comportamentos inspirados na diversidade social, étnica, de gênero e de religiosidade, negando, com isso, o ocultamento destes conhecimentos e tecendo a efetiva mobilização do aprendente para não ser apenas um sujeito de conhecimento, mas, no sentido mais amplo, ser um sujeito de conhecimento cidadão. Afinal, pela prescrição de Metz e Ribeiro (2007, p. 73), “[...] auxiliar os educandos a decifrar, a interpretar e a reinventar o mundo, enquanto sujeitos fazedores da História precisa ser o objetivo de uma prática pedagógica comprometida com a promoção de cidadania”.

Há ainda, a cumplicidade com os saberes da saúde e do autocuidado, pois a Classe, ao estabelecer seus ideários educativos, alinhava, junto a eles, os ritos curativos, manifestando, assim, identidade ao seu entorno. E, por fidelidade à Teoria Crítica, a Classe do Hospital de Clínicas de Porto Alegre problematiza os fatores políticos que assistem ou (des)assistem à saúde e às condições objetivas de qualidade de vida da população.

Neste endereço educacional não há alojamento ao radicalismo, pois o conhecimento escolar ressalta a valorização da cultura do aluno no ritual de seleção dos conteúdos e o mesmo é visto como um processo de construção e conscientização. 
Logo, o currículo manifesto no Programa de Apoio Pedagógico do HCPA versa sobre uma educação que caminha a passos largos rumo à qualidade social, que, na precisão afirmativa de Garcia e Moreira (2006, p. 26-27):

[...] é absolutamente diferente de qualidade total, [...] eu queria completar a ideia de qualidade, completá-la com a ideia de superação [...] Com a busca de alguma coisa melhor, de um mundo melhor, de uma humanidade melhor, de um ser humano melhor. Aí, nesse terreno, chegamos a valores, se não universais, mas valores a respeito dos quais se discuta, valores que se considerem como os mais adequados para a ocasião. Chegamos também a conhecimentos não tão pragmáticos, não tão imediatistas.

O PAP estabelece uma relativização entre as demandas da escola e a planificação possível do hospital. É, em outras palavras, o esforço crítico de silenciar a normatização e a reprodução impostas pelo ensino regular e assinar tratado de resistência, fazendo, inicialmente, escuta aos conhecimentos individuais do aprendiz para depois construir conhecimentos formais que circulam nas disciplinas de Língua Portuguesa, Matemática, Biologia, Química, Física, Filosofia, Língua Estrangeira, Literatura, História, Educação Artística e Psicopedagogia, mediados pelas vantagens das tecnologias de informação e comunicação, tanto no conhecimento em si, quanto para a sua produção/transmissão.

Tal argumentação encontra eco no que está posto por Covic e Oliveira (2011, p. 89):

A escola hospitalar tem um caráter de ser, não se projeta para frente, mas para o ato presente. Os alunos gravemente doentes têm na escola hospitalar o espaço maciço de encontro com o conhecimento que possuem com aqueles sistematizado, histórico e socialmente escolarizados.

Estes encontros de ensino são pautados pelo convite ao diálogo - tão legítimo nas relações democráticas - e pelo respeito genuíno aos saberes do estudante. Pois, a fala, a escuta e o silêncio neste evento protagonizam no infantil doente, na sensível percepção de Silva (2007, p 149), “[...] o desejo de vida, a persistência na luta, a recusa ao fatalismo e a identificação com a esperança, repercutindo em seu restabelecimento e fomentando o processo de aprendizagem".

A avaliação escolar procedida no PAP não está atrelada à aferição de conhecimentos como resultado de um processo endurecido, negando, portanto, o discurso da exclusão e da pregação messiânica daqueles que passarão de ano e aqueles que ficarão reprovados. Faz-se oportuno, na esteira desta discussão, o arrazoado de Arosa (2007, p. 88):

No hospital, o professor não tem o poder instituído para promover ou reter alunos, ou para classificá-los a partir de critérios estabelecidos a priori. A função clássica da 
O Currículo da Classe Hospitalar Pioneira no Rio Grande do Sul

avaliação, ou seja, de exercer o controle, materializado na disciplinarização dos corpos e mentes; no espaço educativo hospitalar não tem sentido.

Além do mais, alocando o pensamento de Schilke e Nunes (2008, p.44), nota-se que "[...] normalmente não existe, no hospital, na maioria das vezes, permanência do grupo de alunos o tempo suficiente para justificar a preocupação com progressão através dos anos; nem existe, neste contexto, a função de certificar a vivência escolar”.

O processo avaliativo adotado na Classe Hospitalar pioneira é reflexão, observa o planejamento no passado, no presente e, como luneta visionária, vislumbra o tempo futuro.

Nesta lógica, o trabalho avaliativo da escola hospitalar, numa concepção crítica - que trafega pela politização do ato educativo e a problematização da realidade - olha para si, para o entorno, para o processo de construção do conhecimento, para a filiação metodológica, com vistas a pensar acerca do que fizeram e do que podem fazer. Logo, a avaliação escolar do PAP carrega uma vertente política, estando sua prática em sintonia à identidade de seus objetivos materializados.

No entanto, a educação hospitalar ainda é considerada uma proposta marginal no campo da educação, é preciso subverter este signo, disponibilizando reflexões que toquem neste estranhamento e atinjam a materialidade de políticas efetivamente mais democráticas acerca da educação de todas as crianças e jovens.

É preciso, pois, ousar o alargamento de fronteiras, não estabelecendo a discussão apenas no veio nuclear da própria prática da classe hospitalar e sim promovendo o avanço desta interlocução nos sistemas escolares, nas classes hospitalares, no campo legislativo, nos cursos de formação de professores, nos projetos de ensino e pesquisa da academia e nos espaços de socialização científicos consagrados tanto na área educacional quanto na da saúde.

A garantia de direitos é uma prerrogativa a ser alcançada, porém é necessário ampliar este entendimento. Há certo silenciamento quanto ao ideário da classe hospitalar; seu caminho independente ainda precisa ser escrito.

Existe uma relação muito próxima entre a escola e a classe, e esta relação potencializa alguns entraves no momento da definição dos conteúdos escolares. Institucionalmente, o currículo da classe hospitalar vê-se refém da instituição escolar de origem, que nomeia os conteúdos, ações e valores que satisfazem a escola e o modelo de sociedade desejada, cabendo pouco espaço para a definição autônoma por parte dos professores do hospital.

Tais pistas revertem-se em mapa de identificação para a classe hospitalar, que, cumprindo equivalente ofício de ensino, não possui o mesmo aparato legal e proteção institucional da educação regular, sendo, pois, secundarizada, colocada num lugar de solidão na vertente educacional. 
Talvez recaia aí o maior pleito da classe hospitalar: reconhecimento de seu currículo, respeitabilidade quanto ao seu fazer nas políticas públicas, estar num lugar compartilhado e não ter vida educacional heterônoma.

\section{Aquilo que se Desvela como Manifestos Finais}

A aposta de ensino do Programa de Apoio Pedagógico evidencia opção curricular crítica, associada a uma concepção de aluno, para além do instituído paciente. Portanto, o instituinte é ser sujeito crítico e autônomo. Este precisa acreditar na emancipação, ter a posse não só dos conhecimentos sistematizados, mas ser um conhecedor das desigualdades sociais e culturais, das múltiplas faces do poder e das tramas que impedem a igualdade entre os humanos.

Desta forma, a caminhada educacional da Classe Hospitalar gaúcha dá passagem aos três segmentos fundamentais do currículo: informação, formação e vivências.

O segmento da informação corporifica-se com a demanda de conhecimentos técnicos voltados ao desenvolvimento acadêmico do aluno e veiculados na Classe Hospitalar pesquisada.

O PAP demarca a crença de que o conhecimento disponibilizado em seu fazer cumpre um ofício na melhoria da qualidade de vida dos alunos e também registra a certeza quanto ao papel de alavancar a inclusão socioeducacional dos mesmos.

As disciplinas escolares tradicionais como Língua Portuguesa, Matemática, Biologia, Química, Física, Filosofia, Língua Estrangeira, Literatura, História, Educação Artística e Psicopedagogia estão presentes na feitura curricular da classe pioneira, bem como o acréscimo nesta seara dos conhecimentos advindos da área da saúde e do autocuidado.

Outros saberes também são convidados a comporem o rol de conhecimentos compartilhados no espaço de ensino hospitalar. A pluralidade de culturas, sejam elas eruditas - com sua feição clássico-humanista - sejam elas populares - marcadas pela cotidianeidade representam fontes ricas de aprendizagem.

A pluralidade também se manifesta nos saberes e nos comportamentos sublinhados na diversidade social, étnica, de gênero e de religiosidade, sendo esta objeto de escuta singular na estrutura pedagógica da classe gaúcha.

Ainda, por possuírem uma identidade contemporânea, a classe estudada incorpora em seu veio a aceleração, a versatilidade e os novos modos de ensinar, aprender e conviver das tecnologias de informação e comunicação.

Quanto ao segmento da formação e vivências, apregoa-se o contrato de normas de convivência dinamizadas no PAP, instituídas nas estruturas do social e que vislumbram o desenvolvimento do aluno quanto ao seu comportamento em sociedade.

Educação \& Realidade, Porto Alegre, v. 39, n. 2, p. 595-616, abr./jun. 2014. 
O Currículo da Classe Hospitalar Pioneira no Rio Grande do Sul

Toda a ação educacional da Classe Hospitalar do Hospital de Clínicas de Porto Alegre traz a mesma marca, observada desde a missão do hospital e seus objetivos, os condicionantes do processo pedagógico até chegar à expectativa de identidade futura da assistência de ensino. Tal marca é transmitida pelo mesmo fio condutor: a cidadania.

Ao longo do projeto educacional da classe pioneira - pautado em contingência emancipatória -, vê-se a observância do respeito à dignidade, aos valores sociais, à produção cognitiva e ao estado clínico-emocional de cada paciente.

O aluno como sujeito político, solidário, conhecedor, inventivo, cidadão e livre, eis a entidade sonhada e tencionada pela prática curricular desta Classe Hospitalar pesquisada.

Neste sentido, o PAP sedimenta seu percurso na aprendizagem de valores, tendo como sinalização fundante a dialogicidade, para disponibilizar, em seu território de ensino, vivências que potencializem consequências sociais como a justiça, a democracia e a liberdade.

Num caráter de transitoriedade, os espaços de estudo sistematizados no HCPA não ficaram paralisados na abordagem curricular crítica; há uma passagem consentida aos novos pressupostos advogados pela abordagem curricular pós-crítica. Como comprobatório do trânsito na vertente curricular pós-crítica, o ensino na Classe Hospitalar pioneira no Rio Grande do Sul faz a escuta aos novos meios comunicacionais contemporâneos, às vozes das culturas e da diversidade social, étnica, de gênero e de religiosidade, às relações de igualdade aos diferentes e faz, também, acordos com a hibridização.

Logo, a vocação do PAP não é substabelecer uma corrente curricular, mas, antes, caminhar livremente entre elas, cartografando uma territorialidade não de ausências e sim de conhecimentos aceitos e ouvidos.

Tem-se como revelação, ainda, que os fazeres pedagógicos da Classe Hospitalar pioneira no Rio Grande do Sul selam uma aposta na educação do olhar e da escuta - protagonizada ao atendimento de uma comunidade tão singular - e professam a tessitura de um currículo impregnado de vida.

Recebido em 22 de outubro de 2012 Aprovado em 07 de junho de 2013

\section{Nota}

10 estudo discutiu o trabalho curricular presente na classe hospitalar, não se atendo às ações do atendimento pedagógico domiciliar.

\section{Referências}

AROSA, Armando C. Avaliação da Aprendizagem no Espaço Hospitalar. In: AROSA, Armando C.; SCHILKE, Ana Lúcia (Org.). A Escola no Hospital: espaço de experiências emancipadoras. Niterói: Intertexto, 2007. P. 83-94. 
ASSIS, Walkíria de. Classe Hospitalar: um olhar pedagógico singular. São Paulo: Phorte, 2009.

BRASIL. Política Nacional de Educação Especial. Livro 01. Brasília: Ministério da Educação e do Desporto/Secretaria de Educação Especial, 1994a.

BRASIL. Plano de Expansão e Melhoria da Educação Especial. Brasília: Ministério da Educação e do Desporto/Secretaria de Educação Especial, 1994b.

BRASIL. Ministério da Justiça. Resolução n. 41, de outubro de 1995. Declaração dos Direitos da Criança e do Adolescente Hospitalizados. Conselho Nacional dos Direitos da Criança e do Adolescente. Brasília, 1995.

BRASIL. Conselho Nacional de Educação. Resolução n. 02, de 11 de setembro de 2001. Diretrizes Nacionais para a Educação Especial na Educação Básica. Diário Oficial da União, no 177, seção 1 E, de 14 set. 2001, p. 39-40. CEB/CNE. Brasília, DF: Imprensa Oficial. 2001.

BRASIL. Classe Hospitalar e Atendimento Pedagógico Domiciliar: estratégias e orientações. Brasília: Ministério da Educação/Secretaria de Educação Especial, 2002. BRASIL. Conselho Nacional de Educação. Resolução n. 04, de 02 de outubro de 2009. Diretrizes Operacionais para o Atendimento Educacional Especializado na Educação Básica, modalidade Educação Especial. Diário Oficial da União, seção 1, de 05 out. 2009, p. 17. CEB/CNE. Brasília, DF: Imprensa Oficial. 2009.

CAIADO, Kátia R. M. O Trabalho Pedagógico no Ambiente Hospitalar: um espaço em construção. In: RIBEIRO, Maria Luisa Sprovieri; BAUMEL, Roseli Cecília Rocha de Carvalho (Org.). Educação Especial: do querer ao fazer. São Paulo: Avercamp, 2003. P. 71-79

CECCIM, Ricardo Burg et al. Escuta Pedagógica à Criança Hospitalizada. In: CECCIM, Ricardo Burg; CARVALHO, Paulo R. Antonacci (Org.). Criança Hospitalizada: atenção integral como escuta à vida. Porto Alegre: Editora da Universidade/UFRGS, 1997. P. 76-84.

COVIC, Amália Neide; OLIVEIRA, Fabiana Aparecida de Melo. O Aluno Gravemente Enfermo. São Paulo: Cortez, 2011.

DOMINGUES, José Luiz. Interesses Humanos e Paradigmas Curriculares. Revista Brasileira de Estudos Pedagógicos, Brasília, v. 67, n. 156, p. 361-66, maio/ ago. 1986.

FONSECA, Eneida Simões da. Implantação e implementação de espaço escolar para crianças hospitalizadas. Revista Brasileira de Educação Especial, v. 8, n. 2, p. 205-215, 2002.

FONTES, Rejane de Souza. A Reinvenção da Escola a partir de uma Experiência Instituinte em Hospital. Educação e Pesquisa, São Paulo, v. 30, n. 2, p. 271-282, maio/ago. 2004.

GARCIA, Regina Leite; MOREIRA, Antonio Flávio Barbosa. Começando uma Conversa sobre Currículo. In: GARCIA, Regina Leite; MOREIRA, Antonio Flávio Barbosa (Org.). Currículo na Contemporaneidade: incertezas e desafios. 2. ed. São Paulo: Cortez, 2006. P. 07-39.

GOODSON, Ivor F. Currículo: teoria e história. 4. ed., Petrópolis: Vozes, 2001. HEIDEGGER, Martin. Ser e Tempo - parte I. 6. ed., Petrópolis: Vozes, 1997.

LOPES, Alice Casimiro; MACEDO, Elizabeth. O Pensamento Curricular no Brasil. In: LOPES, Alice Casimiro; MACEDO, Elizabeth (Org.). Currículo: debates contemporâneos. São Paulo: Cortez, 2002. P. 13-54.

Educação \& Realidade, Porto Alegre, v. 39, n. 2, p. 595-616, abr./jun. 2014.

Disponível em: <http://www.ufrgs.br/edu_realidade> 
MACEDO, Elizabeth Fernandes de. Novas Tecnologias e Currículo. In: MOREIRA, Antonio Flávio Barbosa (Org.). Currículo: questões atuais. 9. ed. Campinas: Papirus, 2003. P. 39-58.

MACEDO, Roberto Sidnei. Currículo: campo, conceito e pesquisa, Petrópolis: Vozes, 2007.

METZ, Patrícia Ponte; RIBEIRO, Rosana. A Prática Pedagógica e o Currículo no Hospital: reflexões sobre uma ação educativa emancipadora. In: AROSA, Armando C.; SCHILKE, Ana Lúcia (Org.). A Escola no Hospital: espaço de experiências emancipadoras. Niterói: Intertexto, 2007. P. 69-82.

MOREIRA, Antonio Flávio Barbosa. A Crise da Teoria Curricular Crítica. In: COSTA, Marisa Vorraber (Org.). O Currículo nos Limiares do Contemporâneo. 4. ed. Rio de Janeiro: DP\&A, 2005. P. 11-36.

MOREIRA, Antonio Flávio Barbosa; SILVA, Tomaz Tadeu da. Sociologia e Teoria Crítica do Currículo: uma introdução. In: MOREIRA, Antonio Flávio Barbosa; SILVA, Tomaz Tadeu da (Org.). Currículo, Cultura e Sociedade. 10. ed. São Paulo: Cortez, 2008. P. 07-37.

REZENDE, Antonio Muniz de. Concepção Fenomenológica da Educação. São Paulo: Cortez: Autores Associados, 1990.

SACRISTÁN, J. Gimeno. Educar e Conviver na Cultura Global: as exigências da cidadania. Porto Alegre: Artmed, 2002.

SAVIANI, Nereide. Saber Escolar, Currículo e Didática: problemas da unidade conteúdo/método no processo pedagógico. 5. ed. Campinas: Autores Associados, 2006.

SCHILKE, Ana Lucia; NUNES, Lauane Baroncelli. Avaliação da Aprendizagem no Hospital: tensões ideológicas. In: AROSA, Armando C.; SCHILKE, Ana Lúcia (Org.). Quando a Escola é no Hospital. Niterói: Intertexto, 2008. P. 41-50.

SILVA, Tomaz Tadeu da. Documentos de Identidade: uma introdução às teorias do currículo. 2. ed. Belo Horizonte: Autêntica, 2001.

SILVA, Fátima Júlia Martins da. A Ação Educativa no Hospital: desafios e possibilidades. In: AROSA, Armando C.; SCHILKE, Ana Lúcia (Org.). A Escola no Hospital: espaço de experiências emancipadoras. Niterói: Intertexto, 2007. P. 147-157.

UCHÔA, Janete. O Trabalho Pedagógico na Sala de Espera: uma experiência em construção. In: AROSA, Armando C.; SCHILKE, Ana Lúcia (Org.). A Escola no Hospital: espaço de experiências emancipadoras. Niterói: Intertexto, 2007. P. 159-167.

Leodi Conceição Meireles Ortizé pedagoga, especialista em Pesquisa, mestre em Educação, doutora em Educação pela Universidade Federal de Santa Maria e coordenadora do Setor Educacional do Hospital Universitário de Santa Maria, na Universidade Federal de Santa Maria.

E-mail: leodiortiz@yahoo.com

Soraia Napoleão Freitas é educadora especial, especialista em Psicomotricidade, mestre em Educação Brasileira, doutora em Educação, pós-doutora em Educação e professora associada do Departamento de Educação Especial do Centro de Educação, da Universidade Federal de Santa Maria. E-mail: soraianfreitas@yahoo.com.br 